\title{
General Psychiatry Extending the neurocircuitry of behavioural inhibition: a role for the bed nucleus of the stria terminalis in risk for anxiety disorders
}

\author{
Jacqueline Clauss (D) ${ }^{1,2}$
}

To cite: Clauss J. Extending the neurocircuitry of behavioural inhibition: a role for the bed nucleus of the stria terminalis in risk for anxiety disorders. General Psychiatry 2019;32:e100137. doi:10.1136/ gpsych-2019-100137

Received 13 October 2019 Revised 11 November 2019 Accepted 13 November 2019

Check for updates

(c) Author(s) (or their employer(s)) 2019. Re-use permitted under CC BY-NC. No commercial re-use. See rights and permissions. Published by BMJ.

${ }^{1}$ Child and Adolescent Psychiatry, Massachusetts General Hospital, Boston, Massachusetts, USA

${ }^{2}$ Child and Adolescent Psychiatry, McLean Hospital, Belmont, Massachusetts, USA

Correspondence to Dr Jacqueline Clauss; jclauss@partners.org

\section{ABSTRACT}

Behavioural inhibition is a biologically based risk factor for anxiety disorders. Children with behavioural inhibition are shy, cautious and avoidant of new situations. Much research on behavioural inhibition has focused on the amygdala as an underlying neural substrate and has identified differences in amygdala function and volume; however, amygdala findings have yet to lead to meaningful interventions for prevention or treatment of anxiety disorders. The bed nucleus of the stria terminalis (BNST) is a prime candidate to be a neural substrate of behavioural inhibition, given current evidence of BNST function and development in human research and animal models. Children with behavioural inhibition have an increased startle response to safety cues and an increased cortisol response to social evaluative situations, both of which are mediated by the BNST. In rodents, activation of the BNST underlies contextual fear responses and responses to uncertain and sustained threat. Non-human primates with anxious temperament (the macaque equivalent of behavioural inhibition) have increased BNST activity to ambiguous social situations, and activity of the BNST in anxious temperament is significantly heritable. Importantly, the BNST is sexually dimorphic and continues to develop into adulthood, paralleling the development of anxiety disorders in humans. Together, these findings suggest that further investigation of the BNST in behavioural inhibition is necessary and may lead to new avenues for the prevention and treatment of anxiety disorders.

\section{ANXIETY DISORDERS}

Anxiety disorders are chronic, ${ }^{1}$ highly impairing $^{2-4}$ and associated with the development of comorbid mood and substance use disorders. ${ }^{5-7}$ Individuals with anxiety disorders rarely seek treatment (approximately one in five individuals with an anxiety disorder seek treatment in both the USA and China) ${ }^{89}$ and responses to current treatments are modest at best. ${ }^{1011}$ The estimated cost of anxiety disorders in America alone is over US $\$ 45$ billion. ${ }^{12} 13$ Given this substantial societal burden of anxiety disorders, more work is needed to prevent and treat these devastating diseases. Understanding the neurobiology of risk for anxiety disorders is a critical first step.

\section{Behavioural inhibition}

Anxiety disorders are often preceded by behavioural inhibition, ${ }^{14-17}$ the tendency to be shy, cautious and avoidant of novelty. ${ }^{18}$ This temperament begins in infancy as high reactivity to novelty. Infants who are highly reactive to novel stimuli and distressed on separation from their mothers typically become behaviourally inhibited children. ${ }^{18-20}$ Behavioural inhibition represents the most extreme $15 \%$ on a continuum of reactivity to novelty and many, but not all, children with behavioural inhibition develop anxiety disorders later in life. ${ }^{15}$ Behaviourally inhibited children most commonly develop social anxiety disorder; one meta-analysis found that $43 \%$ of behaviourally inhibited children develop social anxiety disorder by late childhood or early adolescence. ${ }^{15}$ However, childhood behavioural inhibition also increases risk for other anxiety disorders, including generalised anxiety disorder, ${ }^{21} 22$ phobias, ${ }^{22-24}$ and agoraphobia. ${ }^{23}$ Childhood behavioural inhibition also increases risk for a number of other known comorbidities of anxiety disorders, including depression ${ }^{22}{ }^{25-27}$ and substance use disorders. ${ }^{28} 29$

Behavioural inhibition can be observed across cultures ${ }^{30} 31$ and is evolutionarily conserved across species, including earthworms, octopuses, non-human primates and others (for a review, see Gosling and $\mathrm{John}^{32}$ ). Additionally, behavioural inhibition is heritable ${ }^{3334}$ and has moderate stability across the lifetime; ${ }^{185}$ taken together, these data suggest that behavioural inhibition has a biological basis. Because behavioural inhibition precedes the onset of anxiety disorders, has a known biological basis and is measurable, understanding the neurobiology of 
behavioural inhibition may allow us to gain traction on the prevention and treatment of anxiety disorders.

In 1988, Dr Jerome Kagan proposed that the biological bases of behavioural inhibition were hyperactivity of the amygdala and hyper-reactivity of the sympathetic nervous system; these changes led to increased reactivity to novelty. ${ }^{36}$ Physiological studies in children with behavioural inhibition have shown that behavioural inhibition is associated with decreased threshold for activation of the sympathetic nervous system, ${ }^{37}$ less parasympathetic input, as measured by a higher and more stable (less variable) heart rate, ${ }^{36} 38-40$ and an increased sympathetic response, as measured by increased heart rate reactivity to stressors, ${ }^{36}{ }^{41}$ larger pupillary diameter, increased laryngeal muscle tension, and increased urinary norepinephrine concentration. ${ }^{36}{ }^{39}$ Cortisol and related hormones (ie, corticotropin-releasing hormone $(\mathrm{CRH}))$ modulate these stress responses (both initiation of the stress response and inhibition through a negative feedback pathway) ${ }^{42}$ and much of the early research into the biological basis of behavioural inhibition focused on the cortisol response.

Several studies of the hypothalamic-pituitary-adrenal (HPA) axis response in behavioural inhibition have found that behavioural inhibition is associated with higher cortisol concentrations at baseline and in response to stress. Inhibited children had significantly higher cortisol concentrations at home and in the laboratory ${ }^{39} 4143$. Pérez-Edgar $e t a l^{44}$ found that behavioural inhibition was associated with higher morning salivary cortisol and that increased cortisol concentration and increased negative affect predicted more social withdrawal behaviour, a precursor of social anxiety. Further investigation showed that increased cortisol concentration in children aged 4 years was significantly associated with increased social withdrawal behaviour, specifically in boys with a history of high negative affect. High cortisol might sustain negative affect and behavioural inhibition in boys with high negative affect early in life. Children with behavioural inhibition may be more sensitive to social stressors, resulting in increased cortisol reactivity-this increased sensitivity to social stressors may be governed by alterations in amygdala, hippocampus and bed nucleus of the stria terminalis (BNST) response. ${ }^{42}$

Another consistent finding in individuals with behavioural inhibition is increased startle reactivity. In response to a sudden and intense stimulus, humans and lower mammals display a sudden eyeblink response. ${ }^{45}$ Infants who were highly reactive to novelty had an increase in startle amplitude when a stranger approached. ${ }^{43}$ Children with behavioural inhibition have a shorter latency to startle response ${ }^{46}$; children with behavioural inhibition who had a larger startle response during safety developed more internalising problems and social anxiety 2 years later. ${ }^{47}$ Adolescents with behavioural inhibition who met criteria for an anxiety disorder had heightened startle to safety cues compared with behaviourally inhibited adolescents without an anxiety disorder, but there were no group differences in startle to fear cues. ${ }^{48}$ Additionally, Schmidt et al found no temperament differences in magnitude of fear-potentiated startle in young children. ${ }^{41}$ These findings suggest that children with behavioural inhibition have elevated startle to safety, but not fear cues, and that heightened startle to safety cues may predict risk for the development of anxiety disorders. Fear-potentiated startle (ie, increased startle after seeing a fearful stimulus) is thought to be mediated by the amygdala, whereas anxiety-potentiated startle (ie, increased startle in a context that might be associated with threat) is thought to be mediated by the BNST. ${ }^{49}$ While safety cues signal the lack of threat in these paradigms, behaviourally inhibited children may interpret the entire startle paradigm as anxiety-provoking and thus have elevated startle to safety cues mediated by BNST activation; however, that hypothesis has yet to be tested at this time. Consistent findings of elevated startle to safety cues in behavioural inhibition suggest that BNST function might be altered in behavioural inhibition.

\section{Neurobiology of behavioural inhibition}

A number of recent manuscripts have reviewed the neurobiological underpinnings of behavioural inhibition. ${ }^{50-52}$ Inhibited temperament was initially described as the tendency to avoid and be wary of novel people, places or things. As the amygdala responds to novel, fearful and salient stimuli in the environment $t^{53} 54$ and has efferent projections to the limbic system, sensory cortex, and brainstem, ${ }^{53-56}$ amygdala hyperactivity was first proposed as the neurobiological basis of inhibited temperament. ${ }^{39} 57$

Early neuroimaging studies found that behavioural inhibition was associated with a faster, ${ }^{58}$ larger $^{50}{ }^{59}$ and more sustained $^{58}$ amygdala response to novel social stimuli. Behavioural inhibition was also associated with increased amygdala response to newly familiar social stimuli ${ }^{60} 61$ and internal reflection about social stimuli. ${ }^{62}$ Consistent with evidence in rodents that sustained stress and increased cortisol activity leads to larger amygdala volume, ${ }^{63-65}$ amygdala volume and activation are increased in young adults with behavioural inhibition. ${ }^{66}$ Despite evidence for amygdala hyperactivity in behavioural inhibition, identifying these changes in amygdala function and structure has not led to differences in treatment or prevention of anxiety disorders. Failure of amygdala findings to lead to changes in prevention or treatment suggests that we should search for additional neurobiological markers of behavioural inhibition.

\section{EVIDENCE FOR THE BNST IN ANXIETY}

\section{Rodent models}

The BNST is a small structure in the medial forebrain which is considered to be part of the 'extended amygdala' (figure 1). The BNST and amygdala have similar connectivity and gene expression profiles ${ }^{67}$ (figures 2 and 3 ). In both rodents and humans, there is an increasing startle response from neutral context, to conditioned stimulus, 


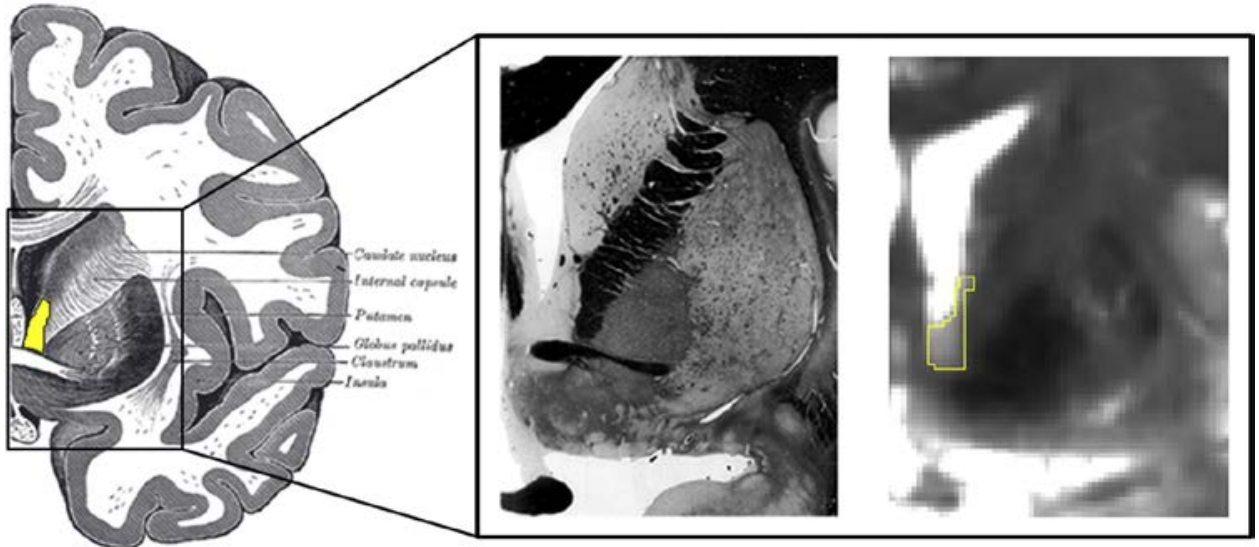

Figure 1 The human bed nucleus of the stria terminalis (BNST). (Left) Human illustration with BNST highlighted in yellow. (Middle) Human fixed tissue slice. (Right) BNST mask on a 7T gradient spin echo MRI image. Used with permission from Avery et $\mathrm{al}^{77}$.

and highest in the contextual fear context; in humans, subjective anxiety also increases from neutral context to predictable threat, to peak at the unpredictable threat context. ${ }^{68}$ Rodents who experience threat in one context then go on to avoid that context. ${ }^{69}$ Increased contextual avoidance in rodents parallels symptoms seen in anxiety disorders and behavioural inhibition (table 1). Alterations in BNST function may underlie the behavioural and physiological changes associated with behavioural inhibition and provide new avenues for treatment and prevention of anxiety disorders. Other recent reviews ${ }^{70} 71$ have described emerging research in the BNST and provide an excellent foundation about this brain region; this review specifically focuses on the relationship of the BNST to developing anxiety disorders.

Decades of research have demonstrated that while the amygdala responds to certain threat or fear stimuli, the BNST responds to uncertainty and sustained threat. ${ }^{49}$ This dichotomy was initially discovered in rodent models using the startle response. Startle magnitude in rodents is larger in bright light (light-enhanced startle; equivalent to darkness for humans) and after hearing a cue previously paired with a shock (fearpotentiated startle) ${ }^{45}$ (table 1 ). BNST lesions reduce the light-enhanced startle response, but do not affect

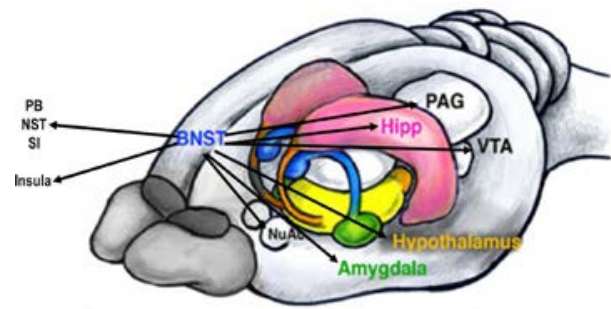

Figure 2 Rodent BNST connectivity. The rodent BNST is connected to a number of limbic, subcortical and cortical regions. Figure adapted from Sokolowski and Corbin $^{96}$. BNST, bed nucleus of the stria terminalis; Hipp, hippocampus; NST, nucleus tractus solitarious; NuAc, nucleus accumbens; PAG, periaqueductal gray; PB, parabrachial nucleus; SI, substantia innominata; VTA, ventral tegmental area. the fear-potentiated startle response. ${ }^{45}$ Infusion of CRH into the BNST increases the magnitude of both fearpotentiated startle ${ }^{72}$ and startle in response to contextual fear (environment in which shock has occurred). ${ }^{69}$ Rodents with BNST lesions have lower conditioned fear responses to long-duration conditioned stimuli (10 min between conditioned stimulus and unconditioned stimulus), which may represent a period of persistent anxiety or uncertain threat. ${ }^{73}$

Other phenotypes associated with behavioural inhibition have also been shown in rodent models to be related to BNST function. BNST lesions decrease latency to enter and increase exploration time in the open arm of an elevated zero maze, another model of avoidance of novelty and anxiety in rodents. ${ }^{73}$ Social defeat (ie, an animal's failure to continue to defend itself after being defeated by a rival) is mediated by CRH activity in the BNST $^{74}$ and animals experiencing inescapable shock do not give up escaping their cage if they have BNST lesions. ${ }^{49}$ Mounting evidence in rodent models suggests

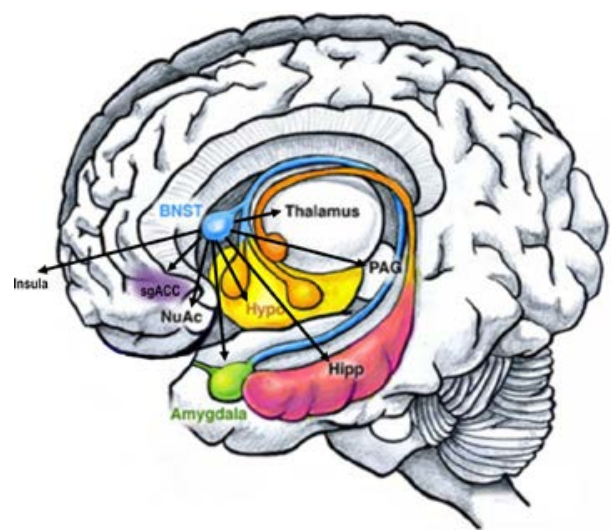

Figure 3 Human BNST connectivity. The human BNST has been shown to be functionally and structurally connected to similar regions as the rodent BNST, and to additional cortical regions. Adapted from Sokolowski and Corbin ${ }^{96}$. BNST, bed nucleus of the stria terminalis; Hipp, hippocampus; NuAc, nucleus accumbens; PAG, periaqueductal gray; sgACC, subgenual anterior cingualte cortex. 
Table 1 Relationship of anxiety disorders to BNST characteristics

\section{Characteristic of anxiety disorder}

Avoidance and anxiety about unpredictable situations

Chronic social stressors can lead to social anxiety

Avoidance of novelty in behavioural inhibition

Hyperstartle in PTSD and other anxiety disorders; increased dark-potentiated startle in PTSD ${ }^{94}$

Onset of anxiety disorders during puberty ${ }^{95}$

Increased rate of behavioural and anxiety disorders in women ${ }^{7}$

\section{Characteristic of BNST}

Increased BNST activation in patients with anxiety disorders to unpredictable threat. $^{92} 93$

BNST lesions decrease social defeat stress. ${ }^{4974}$

Increased activation of BNST in novel social situations in non-human primates. $^{84}$

BNST mediates startle in contextual fear ${ }^{69}$ and startle under bright light ${ }^{45}$ in rodents.

Changing function and structure of the BNST with sex hormones. ${ }^{49}$

Sexual dimorphism of BNST..$^{90}$

BNST, bed nucleus of the stria terminalis; PTSD, post-traumatic stress disorder.

that BNST activity underlies many of the symptoms seen in anxiety disorders in humans.

\section{Human neuroimaging}

In humans, activation of the BNST has been provoked using virtual reality contexts (table 2). In pioneering work by ${ }^{75}{ }^{76}$ Alvarez et al 75 and Torrisi et al 76 virtual reality contexts have been used to represent certain threat (in which an auditory cue always predicted a shock), uncertain threat (tones and shocks were presented in an unrelated fashion), and neutral contexts (in which tones were presented, but there were no shocks). These virtual reality paradigms can be used inside the functional MRI scanner to replicate predictable and unpredictable threat in rodent paradigms. Prior to the start of the MRI scan, participants were shown each context and instructed on the context-threat pairing. They were instructed that in one context (ie, a bank), the tone would be paired with a shock, in a second context (ie, a casino), the tone and shock would have no relationship, and in a third context (ie, a restaurant), they would hear the tone, but there would be no shock. Between the indoor contexts, participants viewed an outdoor context that represented the intertrial interval. Subjective anxiety increased linearly from neutral context, to the predictable threat context, to the unpredictable context. ${ }^{75}$ Replicating findings in rodents, the predictable threat context activated the amygdala, whereas the unpredictable threat context activated the BNST. ${ }^{75}$

There are a number of methodological challenges in examining BNST differences with functional MRI in humans. The BNST is a small structure $(\sim 1 / 10$ th the size of the amygdala) located in the basomedial forebrain and is difficult to delineate using conventional imaging methods (figure 1). Recent advances in neuroimaging have allowed for smaller voxel sizes and thus more accurate imaging of the $\mathrm{BNST}^{75}$ 77-79 and the BNST has been reliably identified in 3 Tesla MRI scans. ${ }^{80}$

Functional neuroimaging studies of the BNST have demonstrated similar findings in rodents and non-human primates (table 2). The BNST has both structural and

Table 2 Critical studies of human and non-human primate BNST function and connectivity related to behavioural inhibition and anxiety disorders

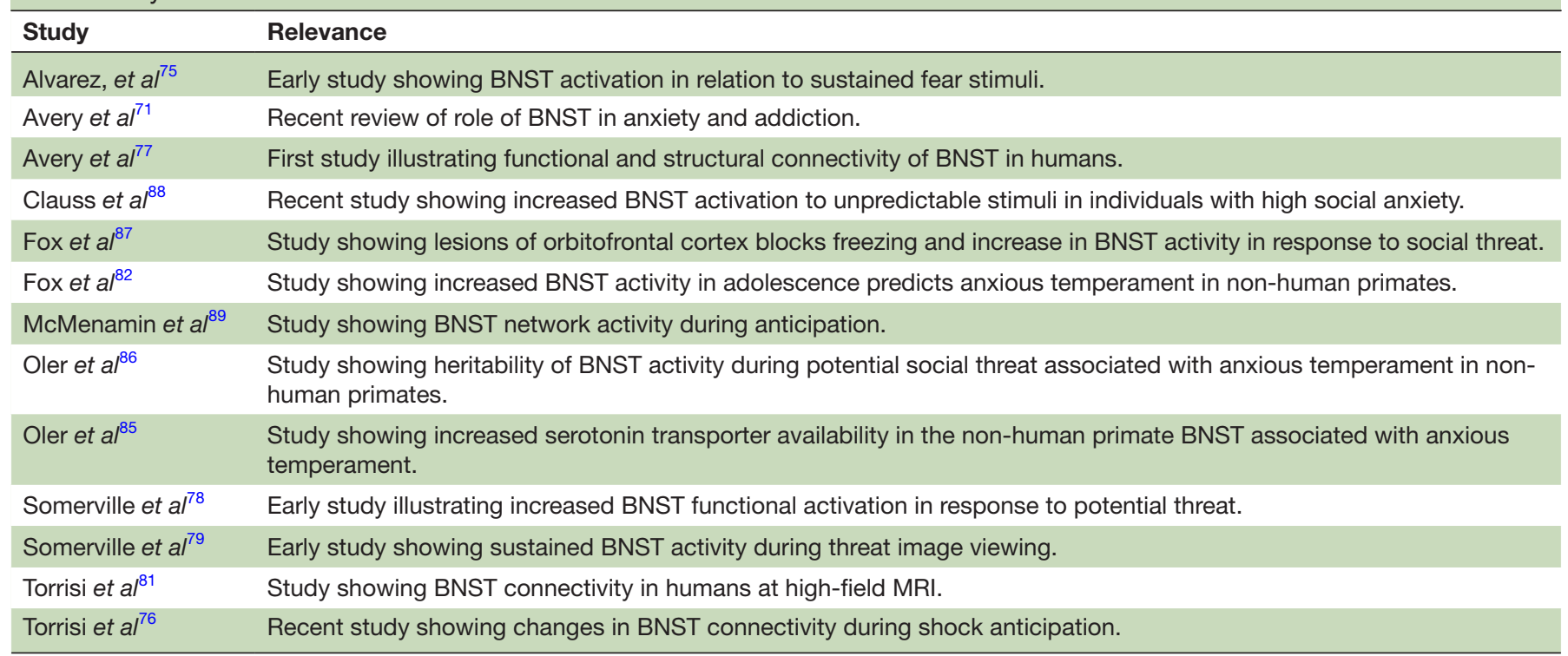

BNST, bed nucleus of the stria terminalis. 
functional connectivity with limbic regions, including the amygdala and hippocampus, the basal ganglia, including nucleus accumbens, caudate and globus pallidus, as well as the thalamus (figure 3). ${ }^{77}$ Additionally, the BNST has significant functional connectivity with the medial prefrontal cortex and insula. ${ }^{77}$ Recently, BNST functional connectivity with the hypothalamus, sublenticular extended amygdala and periaqueductal gray has been demonstrated using ultra high-field functional MRI. ${ }^{81}$

\section{Non-human primate models}

Kalin et al have examined anxious temperament, a nonhuman primate analogue of behavioural inhibition. Anxious temperament is defined as the triad of increased freezing, decreased cooing response, and increased cortisol in response to a non-threatening intruder (unfamiliar human displaying a profile to the macaque and not making eye contact, known as the 'no eye contact' (NEC) paradigm). ${ }^{82} 83$ During the NEC paradigm, the intruder presents an ambiguous potential threat, as the intruder's intentions are not known based on the lack of eye contact. Non-human primate models have several advantages in the study of the neurobiology of anxiety risk. Non-human primate models allow for precisely characterised genetics, mechanistic studies, including precise brain lesion studies and the ability to repeatedly conduct positron emission tomography imaging over time.

Early studies showed that anxious temperament and increased freezing during the NEC paradigm were associated with significantly increased glucose uptake in the BNST (table 2). ${ }^{82} 84$ Additionally, increased serotonin transporter availability in the BNST was associated with anxious temperament and increased glucose uptake during the NEC paradigm. ${ }^{85}$ In a large-scale study examining the heritability of brain activation in anxious temperament, Oler et $a l^{86}$ found that anxious temperament-related activation in the amygdala, insula and BNST was significantly heritable and activation in the BNST during a social task was the most heritable of the brain regions identified. Activation of the orbitofrontal cortex may be a critical component of freezing in anxious temperament. Macaques with orbitofrontal cortex lesions did not display increased freezing in response to the NEC intruder paradigm and did not have increases in BNST activation, suggesting that orbitofrontal cortex influences on the BNST are critical for full expression of the anxious temperament phenotype. ${ }^{87}$

\section{Human behavioural inhibition}

Neuroimaging studies of BNST in humans with behavioural inhibition have been limited. To date, one study in humans with trait social anxiety ${ }^{88}$ showed that across all subjects, the BNST activates to social stimuli following a positive or negative cue (ie, unpredictable valence). Individuals with higher social anxiety had an increased BNST response to unpredictable images. Individuals with more social anxiety also had increased connectivity between the BNST with both the posterior cingulate cortex and ventromedial prefrontal cortex when viewing unpredictable threat images. This study provides preliminary evidence for a role of the BNST in a phenotype similar to behavioural inhibition. Tasks that activate the BNST, such as those that evoke uncertainty and potential threat, should be used in inhibited temperament to test for differences in BNST activation.

\section{FUTURE DIRECTIONS}

The BNST does not function in isolation and a number of recent studies have examined connectivity of the BNST in humans. ${ }^{76} 7789$ BNST connectivity is likely to also be altered in behavioural inhibition and patterns of change in BNST connectivity may shed light on anxiety risk. Applying virtual reality paradigms such as those in the study by Grillon $e t a l^{756}$ may be helpful in understanding differences in BNST neurocircuitry in behavioural inhibition.

The BNST is sexually dimorphic ${ }^{90}$ and sex hormones can alter BNST structure and function. ${ }^{49}$ Given that anxiety disorders are more common in females, ${ }^{7}$ alterations in BNST structure and response to sex hormones may mediate some of these gender differences. Sexual differentiation of the BNST in humans may extend into adulthood. ${ }^{91}$ As the BNST continues to develop throughout puberty, understanding these changes in BNST development may also help us to understand anxiety disorder risk, as many anxiety disorders have their onset during puberty.

\section{SUMMARY}

A number of factors point to the BNST as a critical mediator of behavioural inhibition and anxiety risk (see tables 1 and 2), including its relationship to contextual fear and anxiety, cortisol response and hyperstartle. Understanding alterations in BNST response may lead to new avenues for treatment and prevention of anxiety disorders. Exploring the development of BNST over time in human subjects and changes in the patterns of BNST connectivity may provide critical information regarding the development of anxiety disorders.

Acknowledgements The author would like to thank Dr Philip Cawkwell for helpful feedback on the manuscript. The author would like to thank Dr Jennifer Blackford and Dr Suzanne Avery for their helpful discussions about the BNST and behavioural inhibition.

Contributors $\mathrm{JC}$ developed the ideas, wrote the manuscript and edited the manuscript. JC conceived and wrote the current manuscript.

Funding JC is supported by the MGH/McLean Research Concentration Program (NIMH R25-MH094612) and by NIMH 3-R01-MH109562-04S1.

Competing interests None declared.

Patient consent for publication Not required.

Provenance and peer review Commissioned; externally peer reviewed.

Open access This is an open access article distributed in accordance with the Creative Commons Attribution Non Commercial (CC BY-NC 4.0) license, which permits others to distribute, remix, adapt, build upon this work non-commercially, and license their derivative works on different terms, provided the original work is properly cited, appropriate credit is given, any changes made indicated, and the use is non-commercial. See: http://creativecommons.org/licenses/by-nc/4.0/. 
ORCID iD

Jacqueline Clauss http://orcid.org/0000-0002-0532-6726

\section{REFERENCES}

1 Yonkers KA, Bruce SE, Dyck IR, et al. Chronicity, relapse, and illness?course of panic disorder, social phobia, and generalized anxiety disorder: Findings in men and women from 8 years of followup. Depress Anxiety 2003;17:173-9.

2 Rapaport MH, Clary C, Fayyad R, et al. Quality-Of-Life impairment in depressive and anxiety disorders. AJP 2005;162:1171-8.

3 Wittchen HU, Beloch E. The impact of social phobia on quality of life. Int Clin Psychopharmacol 1996;11 Suppl 3:15-23.

4 Moitra E, Beard C, Weisberg RB, et al. Occupational impairment and social anxiety disorder in a sample of primary care patients. $J$ Affect Disord 2011;130:209-12.

5 Merikangas KR, Mehta RL, Molnar BE, et al. Comorbidity of substance use disorders with mood and anxiety disorders: results of the International Consortium in psychiatric epidemiology. Addict Behav 1998;23:893-907.

6 Kessler RC, Stang P, Wittchen HU, et al. Lifetime co-morbidities between social phobia and mood disorders in the US national comorbidity survey. Psychol Med 1999;29:555-67.

7 Kessler RC, Chiu WT, Demler O, et al. Prevalence, severity, and comorbidity of 12-month DSM-IV disorders in the National comorbidity survey replication. Arch Gen Psychiatry 2005;62:617-27.

8 Mackenzie CS, Reynolds K, Cairney J, et al. Disorder-specific mental health service use for mood and anxiety disorders: associations with age, sex, and psychiatric comorbidity. Depress Anxiety 2012;29:234-42.

9 Ma X, Xiang Y-T, Cai Z-J, et al. Generalized anxiety disorder in China: prevalence, sociodemographic correlates, comorbidity, and suicide attempts. Perspect Psychiatr Care 2009;45:119-27.

10 Hofmann SG, Smits JA. Cognitive-behavior therapy for adult anxiety disorders: a meta-analysis of randomized placebo-controlled trials 2008;20.

11 Ginsburg GS, Kendall PC, Sakolsky D, et al. Remission after acute treatment in children and adolescents with anxiety disorders: findings from the CAMS. J Consult Clin Psychol 2011;79:806-13.

12 DuPont RL, Rice DP, Miller LS, et al. Economic costs of anxiety disorders. Anxiety 1996;2:167-72.

13 Shirneshan E. Cost of illness study of anxiety disorders for the ambulatory adult population of the United States 2013.

14 Chronis-Tuscano A, Degnan KA, Pine DS, et al. Stable early maternal report of behavioral inhibition predicts lifetime social anxiety disorder in adolescence. J Am Acad Child Adolesc Psychiatry 2009;48:928-35.

15 Clauss JA, Blackford JU. Behavioral inhibition and risk for developing social anxiety disorder: a meta-analytic study. J Am Acad Child Adolesc Psychiatry 2012;51:1066-75.

16 Essex MJ, Klein MH, Slattery MJ, et al. Early risk factors and developmental pathways to chronic high inhibition and social anxiety disorder in adolescence. AJP 2010;167:40-6.

17 Schwartz CE, Snidman N, Kagan J. Adolescent social anxiety as an outcome of inhibited temperament in childhood. J Am Acad Child Adolesc Psychiatry 1999;38:1008-15.

18 Kagan J, Snidman N, Arcus D. Childhood derivatives of high and low reactivity in infancy. Child Dev 1998;69:1483-93.

19 Calkins SD, Fox NA, Marshall TR. Behavioral and physiological antecedents of inhibited and uninhibited behavior. Child Dev 1996;67:523-40.

20 Fox NA, Henderson HA, Rubin $\mathrm{KH}$, et al. Continuity and discontinuity of behavioral inhibition and exuberance: psychophysiological and behavioral influences across the first four years of life. Child Dev 2001;72:1-21.

21 Biederman J, Hirshfeld-Becker DR, Rosenbaum JF, et al. Further evidence of association between behavioral inhibition and social anxiety in children. AJP 2001;158:1673-9.

22 Biederman Jet al. Psychiatric correlates of behavioral inhibition in young children of parents with and without psychiatric disorders. Arch Gen Psychiatry 1990;47:21-6.

23 Biederman J, Rosenbaum JF, Bolduc-Murphy EA, et al. A 3-year follow-up of children with and without behavioral inhibition. J Am Acad Child Adolesc Psychiatry 1993;32:814-21.

24 Hirshfeld DR, Rosenbaum JF, Biederman J, et al. Stable behavioral inhibition and its association with anxiety disorder. J Am Acad Child Adolesc Psychiatry 1992;31:103-11.

25 Gladstone GL, Parker GB. Is behavioral inhibition a risk factor for depression? J Affect Disord 2006;95:85-94.
26 Gladstone GL, Parker GB, Mitchell PB, et al. Relationship between self-reported childhood behavioral inhibition and lifetime anxiety disorders in a clinical sample. Depress Anxiety 2005;22:103-13.

27 Caspi A, Moffitt TE, Newman DL, et al. Behavioral observations at age 3 years predict adult psychiatric disorders: longitudinal evidence from a birth cohort. Arch Gen Psychiatry 1996;53:1033-9.

28 Lahat A, Pérez-Edgar K, Degnan KA, et al. Early childhood temperament predicts substance use in young adults. Trans/ Psychiatry 2012;2:e157.

29 Williams LR, Fox NA, Lejuez CW, et al. Early temperament, propensity for risk-taking and adolescent substance-related problems: a prospective multi-method investigation. Addict Behav 2010;35:1148-51.

30 Meysamie A, Ghalehtaki R, Borjian A, et al. Prevalence of behavioral inhibition among preschool aged children in Tehran, Iran. Acta Med Iran 2014;52:298-302.

31 Scarpa A, Raine A, Venables $\mathrm{PH}$, et al. The stability of inhibited/ uninhibited temperament from ages 3 to 11 years in mauritian children. J Abnorm Child Psychol 1995;23:607-18.

32 Gosling SD, John OP. Personality dimensions in nonhuman animals: a cross-species review. Curr Dir Psychol Sci 1999;8:69-75.

33 Robinson JL, Kagan J, Reznick JS, et al. The heritability of inhibited and uninhibited behavior: a twin study. Dev Psychol 1992;28:1030-7.

34 Dilalla LF, Kagan J, Reznick JS. Genetic etiology of behavioral inhibition among 2-year-old children. Infant Behavior and Development 1994;17:405-12.

35 Kagan J, Moss HA. Birth to Maturity: A Study in Psychological Development. London: Wiley, 1962.

36 Kagan J, Reznick J, Snidman N. Biological bases of childhood shyness. Science 1988;240:167-71.

37 Morris TL, Hirshfeld-Becker DR, Henin A, et al. Developmentally sensitive assessment of social anxiety. Cogn Behav Pract 2004;11:13-28.

38 Coll CG, Kagan J, Reznick JS. Behavioral inhibition in young children. Child Dev 1984;55:1005-19.

39 Kagan J, Reznick JS, Snidman N. The physiology and psychology of behavioral inhibition in children. Child Dev 1987;58:1459-73.

40 Marshall PJ, Stevenson-Hinde J. Behavioral inhibition, heart period, and respiratory sinus arrhythmia in young children. Dev Psychobiol 1998;33:283-92

41 Schmidt LA, Fox NA, Schulkin J, et al. Behavioral and psychophysiological correlates of self-presentation in temperamentally shy children. Dev Psychobiol 1999;35:119-35.

42 Dedovic K, Duchesne A, Andrews J, et al. The brain and the stress axis: the neural correlates of cortisol regulation in response to stress. Neuroimage 2009;47:864-71.

43 Schmidt LA, Fox NA, Rubin KH, et al. Behavioral and neuroendocrine responses in shy children. Dev Psychobiol 1997;30:127-40.

44 Pérez-Edgar K, Schmidt LA, Henderson HA, et al. Salivary cortisol levels and infant temperament shape developmental trajectories in boys at risk for behavioral maladjustment. Psychoneuroendocrinology 2008;33:916-25.

45 Walker DL, Davis M. Double dissociation between the involvement of the bed nucleus of the stria terminalis and the central nucleus of the amygdala in startle increases produced by conditioned versus unconditioned fear. J. Neurosci. 1997;17:9375-83.

46 Barker TV, Reeb-Sutherland BC, Fox NA. Individual differences in fear potentiated startle in behaviorally inhibited children: individual differences in potentiated startle. Dev Psychobiol 2014;56:133-41.

47 Barker TV, Reeb-Sutherland B, Degnan KA, et al. Contextual startle responses moderate the relation between behavioral inhibition and anxiety in middle childhood. Psychophysiology 2015;52:1544-9.

48 Reeb-Sutherland BC, Helfinstein SM, Degnan KA, et al. Startle response in behaviorally inhibited adolescents with a lifetime occurrence of anxiety disorders. J Am Acad Child Adolesc Psychiatry 2009;48:610-7.

49 Walker DL, Toufexis DJ, Davis M. Role of the bed nucleus of the stria terminalis versus the amygdala in fear, stress, and anxiety. Eur $J$ Pharmacol 2003;463:199-216.

50 Clauss JA, Avery SN, Blackford JU. The nature of individual differences in inhibited temperament and risk for psychiatric disease: a review and meta-analysis. Prog Neurobiol 2015;127-128:23-45.

51 Pine DS, Fox NA. Childhood antecedents and risk for adult mental disorders. Annu Rev Psychol 2015;66:459-85.

52 Pérez-Edgar K, Fox N. Behavioral inhibition: integrating theory, research, and clinical perspectives. New York, NY: Springer Science+Business Media, 2018.

53 Blackford JU, Buckholtz JW, Avery SN, et al. A unique role for the human amygdala in novelty detection. Neuroimage 2010;50:1188-93.

54 Fear WPJ. Vigilance, and ambiguity: initial neuroimaging studies of the human amygdala. Curr Dir Psychol Sci 1998;7:177-88. 
55 Ghashghaei HT, Hilgetag CC, Barbas H. Sequence of information processing for emotions based on the anatomic dialogue between prefrontal cortex and amygdala. Neuroimage 2007;34:905-23.

56 LeDoux JE, Iwata J, Cicchetti P, et al. Different projections of the central amygdaloid nucleus mediate autonomic and behavioral correlates of conditioned fear. J. Neurosci. 1988;8:2517-29.

57 Kagan J, Snidman N. The Long Shadow of Temperament. Cambridge, MA: Harvard University Press, 2004.

58 Blackford JU, Avery SN, Shelton RC, et al. Amygdala temporal dynamics: temperamental differences in the timing of amygdala response to familiar and novel faces. BMC Neurosci 2009;10.

59 Schwartz CEet al. Inhibited and Uninhibited Infants "Grown Up": Adult Amygdalar Response to Novelty. Science 2003;300:1952-3.

60 Blackford JU, Avery SN, Cowan RL, et al. Sustained amygdala response to both novel and newly familiar faces characterizes inhibited temperament. Soc Cogn Affect Neurosci 2011;6:621-9.

61 Schwartz CE, Kunwar PS, Greve DN, et al. A phenotype of early infancy predicts reactivity of the amygdala in male adults. $\mathrm{Mol}$ Psychiatry 2012;17:1042-50.

62 Pérez-Edgar K, Roberson-Nay R, Hardin MG, et al. Attention alters neural responses to evocative faces in behaviorally inhibited adolescents. Neuroimage 2007;35:1538-46.

63 Vyas A, Pillai AG, Chattarii S. Recovery after chronic stress fails to reverse amygdaloid neuronal hypertrophy and enhanced anxiety-like behavior. Neuroscience 2004;128:667-73.

64 Vyas A, Mitra R, Shankaranarayana Rao BS, et al. Chronic stress induces contrasting patterns of dendritic remodeling in hippocampal and amygdaloid neurons. J. Neurosci. 2002;22:6810-8.

65 Mitra R, Jadhav S, McEwen BS, et al. Stress duration modulates the spatiotemporal patterns of spine formation in the basolateral amygdala. Proc Natl Acad Sci U S A 2005;102:9371-6.

66 Clauss JA, Seay AL, VanDerKlok RM, et al. Structural and functional bases of inhibited temperament. Soc Cogn Affect Neurosci 2014;9:2049-58.

67 Fox AS, Oler JA, Tromp DPM, et al. Extending the amygdala in theories of threat processing. Trends Neurosci.

68 Grillon C, Baas JP, Lissek S, et al. Anxious responses to predictable and unpredictable aversive events. Behav Neurosci 2004;118:916-24.

69 Sullivan GM, Apergis J, Bush DEA, et al. Lesions in the bed nucleus of the stria terminalis disrupt corticosterone and freezing responses elicited by a contextual but not by a specific cue-conditioned fear stimulus. Neuroscience 2004;128:7-14.

70 Lebow MA, Chen A. Overshadowed by the amygdala: the bed nucleus of the stria terminalis emerges as key to psychiatric disorders. Mol Psychiatry 2016;21:450-63.

71 Avery SN, Clauss JA, Blackford JU. The human BNST: functional role in anxiety and addiction. Neuropsychopharmacology 2016:41:126-41.

72 Lee Y, Davis M. Role of the hippocampus, the bed nucleus of the stria terminalis, and the amygdala in the excitatory effect of corticotropin-releasing hormone on the acoustic startle reflex. $J$. Neurosci. 1997;17:6434-46.

73 Waddell J, Morris RW, Bouton ME. Effects of bed nucleus of the stria terminalis lesions on conditioned anxiety: aversive conditioning with long-duration conditional stimuli and reinstatement of extinguished fear. Behav Neurosci 2006;120:324-36.

74 Jasnow AM, Davis M, Huhman KL. Involvement of central amygdalar and bed nucleus of the stria terminalis corticotropin-releasing factor in behavioral responses to social defeat. Behav Neurosci 2004;118:1052-61.

75 Alvarez RP, Chen G, Bodurka J, et al. Phasic and sustained fear in humans elicits distinct patterns of brain activity. Neuroimage 2011;55:389-400.
76 Torrisi S, Gorka AX, Gonzalez-Castillo J, et al. Extended amygdala connectivity changes during sustained shock anticipation. Trans/ Psychiatry 2018;8.

77 Avery SN, Clauss JA, Winder DG, et al. BNST neurocircuitry in humans. Neuroimage 2014;91:311-23.

78 Somerville LH, Whalen PJ, Kelley WM. Human bed nucleus of the stria terminalis indexes hypervigilant threat monitoring. Biol Psychiatry 2010;68:416-24

79 Somerville LH, Wagner DD, Wig GS, et al. Interactions between transient and sustained neural signals support the generation and regulation of anxious emotion. Cereb Cortex 2013;23:49-60.

80 Theiss JD, Ridgewell C, McHugo M, et al. Manual segmentation of the human bed nucleus of the stria terminalis using $3 \mathrm{~T}$ MRI. Neuroimage 2017;146:288-92.

81 Torrisi S, O'Connell K, Davis A, et al. Resting state connectivity of the bed nucleus of the stria terminalis at ultra-high field: resting state connectivity of BNST. Hum Brain Mapp 2015;36:4076-88.

82 Fox AS, Shelton SE, Oakes TR, et al. Trait-like brain activity during adolescence predicts anxious temperament in primates. PLOS ONE 2008;3:e2570.

83 Kalin N, Shelton S. Defensive behaviors in infant rhesus monkeys: environmental cues and neurochemical regulation. Science 1989;243:1718-21.

84 Kalin NH, Shelton SE, Fox AS, et al. Brain regions associated with the expression and contextual regulation of anxiety in primates. Biol Psychiatry 2005;58:796-804.

85 Oler JA, Fox AS, Shelton SE, et al. Serotonin transporter availability in the amygdala and bed nucleus of the stria terminalis predicts anxious temperament and brain glucose metabolic activity. $J$ Neurosci 2009;29:9961-6.

86 Oler JA, Fox AS, Shelton SE, et al. Amygdalar and hippocampal substrates of anxious temperament differ in their heritability. Nature 2010;466:864-8.

87 Fox AS, Shelton SE, Oakes TR, et al. Orbitofrontal cortex lesions alter anxiety-related activity in the primate bed nucleus of stria terminalis. J Neurosci 2010;30:7023-7.

88 Clauss JA, Avery SN, Benningfield MM, et al. Social anxiety is associated with BNST response to unpredictability. Depress Anxiety 2019;36:666-75.

89 McMenamin BW, Langeslag SJE, Sirbu M, et al. Network organization unfolds over time during periods of anxious anticipation. $J$ Neurosci 2014:34:11261-73.

90 Allen LS, Gorski RA. Sex difference in the bed nucleus of the stria terminalis of the human brain. J Comp Neurol 1990;302:697-706.

91 Chung WCJ, De Vries GJ, Swaab DF. Sexual differentiation of the bed nucleus of the stria terminalis in humans may extend into adulthood. J Neurosci 2002;22:1027-33.

92 Straube T, Mentzel H-J, Miltner WHR. Waiting for spiders: brain activation during anticipatory anxiety in spider phobics. Neuroimage 2007;37:1427-36.

93 Brinkmann L, Buff C, Feldker K, et al. Distinct phasic and sustained brain responses and connectivity of amygdala and bed nucleus of the stria terminalis during threat anticipation in panic disorder. Psychol Med 2017;47:2675-88.

94 Kamkwalala A, Norrholm SD, Poole JM, et al. Dark-Enhanced startle responses and heart rate variability in a traumatized civilian sample: putative sex-specific correlates of posttraumatic stress disorder. Psychosom Med 2012;74:153-9.

95 Kessler RC, Berglund P, Demler O, et al. Lifetime prevalence and age-of-onset distributions of DSM-IV disorders in the National comorbidity survey replication. Arch Gen Psychiatry 2005;62:593-602.

96 Sokolowski K, Corbin JG. Wired for behaviors: from development to function of innate limbic system circuitry. Front Mol Neurosci 2012;5:55.

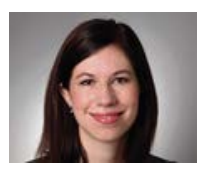

Jacqueline Clauss, M.D, Ph.D., obtained her doctoral degrees from Vanderbilt University and currently serves as a child and adolescent psychiatry fellow at Massachusetts General Hospital/McLean Hospital. Dr. Clauss is an expert in the neurobiological mechanisms implicated in the development of psychiatric disorders, with focuses on building resilience in high risk children and using neuroimaging to understand underlying neurobiology. 